\title{
Chemistry Impacts in Gasoline HCCI
}

\section{Literature Review for CRC PROJECT No. AVFL-13, Fuel}

\author{
ORNL/TM-2006/555 \\ Fuels, Engine, and Emission Research Center \\ Oak Ridge National Laboratory \\ James Szybist and Bruce Bunting
}

September 2006 


\section{CONTENTS}

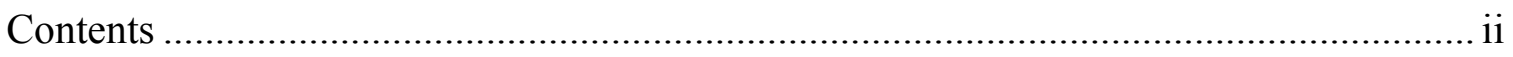

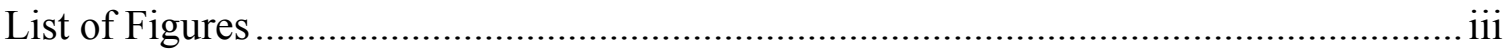

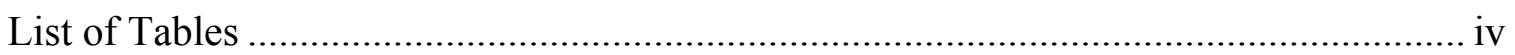

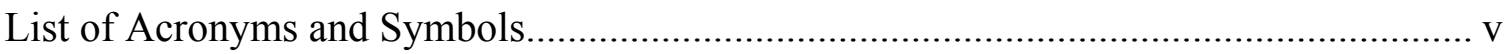

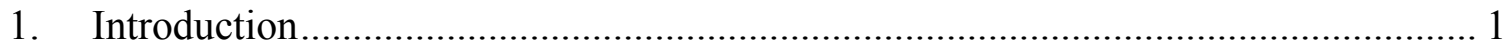

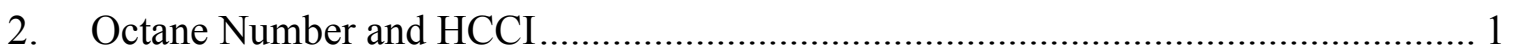

2.1. Low-Temperature Auto-ignition................................................................ 2

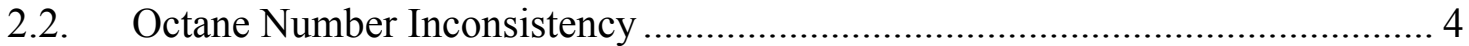

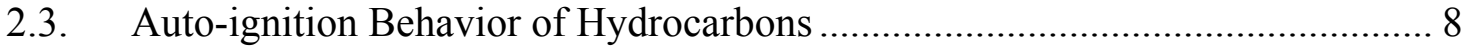

2.4. Octane Number and HCCI .................................................................... 9

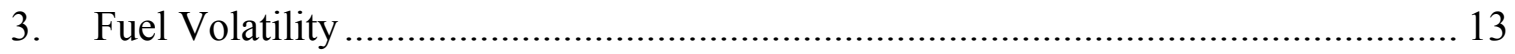

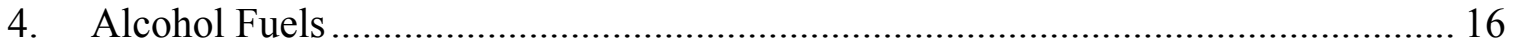

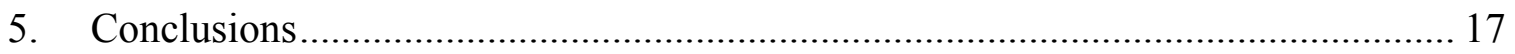

6. Fuel Property Matrix Recommendations ....................................................... 18

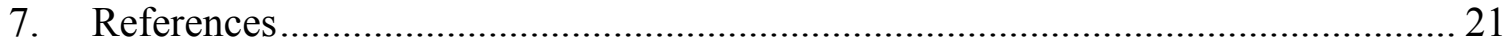




\section{FIGURES}

Figure 1. Effects of engine speed and manifold pressure on low-temperature

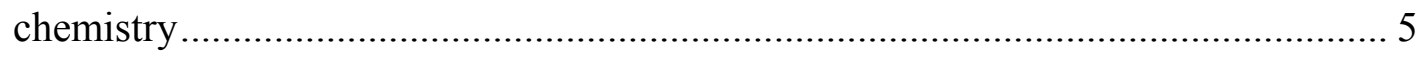

Figure 2. Auto-ignition profiles of hydrocarbons for different engine types ..................... 7

Figure 3. Auto-ignition behavior of various fuels in a rapid compression machine........... 8

Figure 4. Comparison of RON and MON to CAI number ........................................... 10

Figure 5. Operating ranges of fuels at various intake temperatures. ............................... 10

Figure 6. Effects of engine speed for different fuel types of similar octane number ....... 11

Figure 7. $\mathrm{K}$ value for OI calculation as a function of $\mathrm{T}_{\text {comp15 }}$ for various

fuel compositions and engine operating conditions............................................... 12

Figure 8. Comparison of calculated and measured $\mathrm{OI}_{0}$............................................. 13

Figure 9. Operating ranges for FBR gasoline and light and heavy cuts .......................... 14

Figure 10. Surface fraction and homogeneity index of formaldehyde and NOx emissions

for high- and low-volatility fuels as functions of SOI timing................................... 15

Figure 11. Operable ranges for gasoline, methanol, and ethanol at $1500 \mathrm{rpm}$................. 16 


\section{TABLES}

Table 1. Operating parameters of the RON and MON tests........................................ 2

Table 2. Major low-temperature reactions of paraffins .............................................. 3

Table 3. Selected properties of tested gasoline .......................................................... 10

Table 4. Fuel properties of distilled BP gasoline ..................................................... 14 


\section{LIST OF ACRONYMS AND SYMBOLS}

$\begin{array}{ll}\text { BON } & \text { Blending octane number } \\ \text { CAI } & \text { Controlled auto-ignition } \\ \text { CO } & \text { Carbon monoxide } \\ \text { CRC } & \text { Coordinating research council } \\ \text { EGR } & \text { Exhaust gas recirculation } \\ \text { FBR } & \text { Full boiling range } \\ \text { HCCI } & \text { Homogeneous charge compression ignition } \\ \text { IMEP } & \text { Indicated mean effective pressure } \\ \text { KLSA } & \text { Knock limited spark advance } \\ \text { MFB 50 } & \text { 50\% mass fraction burned } \\ \text { MON } & \text { Motor octane number } \\ \text { NOx } & \text { Mixed oxides of nitrogen (mainly nitric oxide and } \\ & \text { nitrogen dioxide) } \\ \text { NTC } & \text { Negative temperature coefficient } \\ \text { OI } & \text { Octane index } \\ \text { PLIF } & \text { Planar laser induced flourescense } \\ \text { PM } & \text { Particulate matter } \\ \mathrm{P}_{\text {maxcomp }} & \text { Maximum compressive pressure } \\ \text { PRF } & \text { Primary reference fuel for octane number rating } \\ \text { RCM } & \text { Rapid compression machine } \\ \text { RON } & \text { Research octane number } \\ \text { RVP } & \text { Reid vapor pressure } \\ S & \text { Octane sensitivity } \\ \text { SI } & \text { Spark ignition } \\ \text { SOI } & \text { Start of injection } \\ \mathrm{T}_{\text {comp } 15} & \text { Compressive temperature at } 15 \text { bar pressure } \\ \text { TDC } & \text { Top dead center } \\ \mathrm{T}_{\text {maxcomp }} & \text { Maximum compressive temperature } \\ \lambda & \text { Lambda: (actual air/fuel ratio) / (stoichiometric } \\ & \text { air/fuel ratio) } \\ & \end{array}$




\section{INTRODUCTION}

The use of homogeneous charge compression ignition (HCCI) combustion in internal combustion engines is of interest because it has the potential to produce low oxides of nitrogen (NOx) and particulate matter (PM) emissions while providing diesellike efficiency. In HCCI combustion, a premixed charge of fuel and air auto-ignites at multiple points in the cylinder near top dead center (TDC), resulting in rapid combustion with very little flame propagation. In order to prevent excessive knocking during HCCI combustion, it must take place in a dilute environment, resulting from either operating fuel lean or providing high levels of either internal or external exhaust gas recirculation (EGR). Operating the engine in a dilute environment can substantially reduce the pumping losses, thus providing the main efficiency advantage compared to spark-ignition (SI) engines.

Low NOx and PM emissions have been reported by virtually all researchers for operation under HCCI conditions. The precise emissions can vary depending on how well mixed the intake charge is, the fuel used, and the phasing of the HCCI combustion event; but it is common for there to be no measurable PM emissions and NOx emissions $<10 \mathrm{ppm}$. Much of the early HCCI work was done on 2-stroke engines, and in these studies the $\mathrm{CO}$ and hydrocarbon emissions were reported to decrease [1]. However, in modern 4-stroke engines, the $\mathrm{CO}$ and hydrocarbon emissions from HCCI usually represent a marked increase compared with conventional SI combustion. This literature review does not report on HCCI emissions because the trends mentioned above are well established in the literature.

The main focus of this literature review is the auto-ignition performance of gasoline-type fuels. It follows that this discussion relies heavily on the extensive information available about gasoline auto-ignition from studying knock in SI engines. Section 2 discusses hydrocarbon auto-ignition, the octane number scale, the chemistry behind it, its shortcomings, and its relevance to HCCI. Section 3 discusses the effects of fuel volatility on fuel and air mixing and the consequences it has on HCCI. The effects of alcohol fuels on HCCI performance, and specifically the effects that they have on the operable speed/load range, are reviewed in Section 4. Finally, conclusions are drawn in Section 5.

\section{OCTANE NUMBER AND HCCI}

Gasoline octane number-usually reported as the mean of the Research Octane Number (RON), measured by ASTM D-2699, and the Motor Octane Number (MON), measured by ASTM D-2700 - is the most widely measured and reported indication of a fuel's ability to resist knock in an SI engine. The tests are performed by setting the engine speed, intake temperature, and spark timing to their respective specified values for the test method. At a given compression ratio, the air-to-fuel ratio is adjusted to maximize knock intensity, which is measured by a knock meter mounted in the cylinder. The compression ratio is then adjusted to achieve a predetermined knocking intensity on the knock meter. The knock intensity must be compared with primary reference fuels with similar octane numbers. The RON and MON tests are performed in the same engine and vary only in the operating conditions shown in Table 1. 
Table 1. Operating parameters of the RON and MON tests

\begin{tabular}{|c|c|c|}
\hline & RON & MON \\
\hline Engine speed (rpm) & 600 & 900 \\
\hline $\begin{array}{c}\text { Spark timing (degrees } \\
\text { before TDC) }\end{array}$ & 13 & $19-26^{1}$ \\
\hline Intake air $\left({ }^{\circ} \mathrm{C}\right)$ & $52^{2}$ & Not controlled \\
\hline Intake charge $\left({ }^{\circ} \mathrm{C}\right)$ & Not controlled & 149 \\
\hline
\end{tabular}

1. Compression ratio dependent

2. Barometric pressure dependent, specified value is for $101.3 \mathrm{kPa}$

The octane number serves as an indication of a fuel's ability to resist knock, or auto-ignition, during SI combustion. Both the RON and MON scales are based on volumetric blends of n-heptane (octane number $=0)$ and iso-octane $(2,2,4-$ trimethylpentane, octane number $=100$ ), which combine to form primary reference fuel (PRF) blends (i.e., PRF 60 is $60 \mathrm{vol} \%$ iso-octane, $40 \mathrm{vol} \% \mathrm{n}$-heptane). In general terms, HCCI combustion is the controlled auto-ignition of a premixed charge of fuel and air through compression, in which there are multiple points of near-simultaneous ignition. This results in no clearly defined boundary between the burned and unburned portion of the fuel, combined with minimum flame front propagation. Thus the auto-ignition of end gas in SI combustion, which causes knock, shares much in common with HCCI combustion, although the temperature pressure history the fuel undergoes is quite different.

Paraffinic fuels, which are the basis for the octane rating scale, undergo a unique set of chemical reactions in low-temperature environments, causing a cool flame and a negative temperature coefficient region. Aromatic and olefinic fuels do not exhibit the same low-temperature behavior, which limits how well octane number predicts knock during SI combustion and auto-ignition during HCCI combustion.

The remainder of Section 2 is sub-divided so that the relationship between octane number and HCCI combustion can be understood. Section 2.1 reviews low-temperature chemistry, which is responsible for cool flames in paraffinic fuels and plays an important role in auto-ignition behavior and in the octane rating scale itself. The ramifications of the low-temperature chemistry are discussed in Section 2.2, where the inadequacies of the octane number rating scale are discussed, especially when it is applied to non-paraffinic fuels. Section 2.3 describes the results of auto-ignition experiments on different classes of hydrocarbons and the interactions between the different fuel types. And finally, Section 2.4 discusses the relationship between octane number and HCCI combustion by reviewing earlier studies.

\subsection{Low-Temperature Auto-ignition}

Curran and coworkers performed comprehensive modeling studies of the oxidation of n-heptane and iso-octane that were validated with data from shock tubes, flow reactors, rapid compression machines, and motored engines [2, 3]. Although there is a substantial difference in the ease with which the fuels auto-ignite, as indicated by their respective octane numbers of 0 and 100, they share a set of low-temperature reactions 
that are unique to paraffins. The temperature at which these reactions occur is dependent on pressure, with reactions beginning at roughly $550 \mathrm{~K}$ at atmospheric pressure and at 600-800 K under typical engine operating pressures [4]. Regardless of the actual temperature, it will be referred to as the cool-flame or low-temperature chemistry.

The major pathways for low-temperature reactions were taken from Curran and coworkers $[2,3]$ and are outlined in Table 2 . An initiation step abstracts a hydrogen atom from a parent paraffin molecule (1), after which there is an oxygen addition to the alkyl radical (2) to form an alkylperoxy radical. This radical undergoes an internal isomerization to form an alkylhydroperoxy radical (3). The alkylhydroperoxy radical can then undergo decomposition to form a carbonyl, a shorter alkyl radical, and a hydroxyl radical (4). Alternatively, the alkylhydroperoxy radical formed in reaction (3) can be attacked by another oxygen molecule (5), followed by an additional internal hydrogen abstraction through isomerization (6). The second hydrogen abstraction forms a ketone group on the site of the original hydrogen addition and forms another hydroxyl radical (7).

Table 2. Major low-temperature reactions of paraffins. Source: Curran and coworkers [2,3]

$$
\begin{aligned}
& \mathrm{RH}+\mathrm{O}_{2} \rightarrow \mathrm{R} \bullet+\mathrm{HO}_{2} \\
& \mathrm{R} \bullet+\mathrm{O}_{2} \rightarrow \mathrm{ROO} \bullet \\
& \mathrm{ROO} \bullet \rightarrow \bullet \mathrm{ROOH} \\
& \bullet \mathrm{ROOH} \rightarrow \mathrm{Carbonyl}+\mathrm{R}^{\prime} \bullet+\mathrm{OH} \bullet \\
& \cdot \mathrm{ROOH}+\mathrm{O}_{2} \rightarrow \bullet \mathrm{OOROOH} \\
& \bullet \mathrm{OOROOH} \rightarrow \mathrm{HOOR}=\mathrm{O}+\mathrm{OH} \bullet \\
& \mathrm{HOORO} \rightarrow \bullet \cdot \mathrm{ORO}+\mathrm{OH} \bullet
\end{aligned}
$$

The net effect of this reaction mechanism is the formation of hydroxyl radicals at low temperatures. The hydroxyl radicals formed in reactions (4), (6), and (7) continue to propagate chain branching through a variety of mechanisms, including abstracting a hydrogen atom to form water and releasing heat. However, as the temperature increases as a result of a combination of heat release and compression, reaction (2) is no longer favored in the forward direction, which stops the low-temperature chemistry. The period when reaction (2) is no longer favored is commonly referred to as the negative temperature coefficient (NTC) regime because the overall rate of reaction decreases with increased temperature.

A major feature of the low-temperature set of reactions with paraffins is the internal isomerization in reactions (3) and (6), which proceeds through a transition state ring structure, to abstract a hydrogen atom internally. Straight chain paraffins can easily form the necessary ring structures for isomerization because they can form the ring structures with sufficiently low ring strain. The rate at which these reactions proceed for highly branched paraffins is slower than the rate for straight chain paraffins because of steric hindrances with internal isomerization, but it remains a major feature of their autoignition process. If olefins or aromatics have long aliphatic chains, that portion of the molecule participates in the low-temperature reactions outlined above. However, if the molecule is small and the aromatic ring or double bond is the dominant feature of the molecule, it will not be able to form the intermediate ring structures necessary to participate in the low-temperature reactions [4]. 
Olefins and aromatics do have their own sets of low-temperature reactions [4]. The low-temperature olefin reactions involve the addition of hydroxyl radicals and oxygen to the double bond site, causing the molecule to cleave to form two aldehydes. The low-temperature aromatic mechanism involves the addition of oxygen across the aromatic ring structure, eventually causing the ring structure to cleave into two smaller molecules. However, for both of these cases, the reaction rates are slow; and both olefins and aromatics are observed to be unreactive at low temperatures in motored engine environments [5].

Thus paraffinic fuels are more reactive in low-temperature environments than both aromatic and olefinic fuels, and the PRF blends for the RON and MON tests consist entirely of paraffins. Because of this, the paraffinic low-temperature behavior is the standard chemistry for octane rating. This distinction, as clarified in the next section, is very important to understanding the octane rating scale.

\subsection{Octane Number Inconsistency}

The presence of two octane number tests, RON and MON, indicates that the propensity of a fuel to knock can be dependent on engine conditions. The lowtemperature chemistry discussed in Section 2.1 is responsible for the difference in the RON and MON ratings. In the RON test, the intake temperature and engine speed are both low $\left(52^{\circ} \mathrm{C}\right.$ and $\left.600 \mathrm{rpm}\right)$ compared with the conditions of the MON test $\left(149^{\circ} \mathrm{C}\right.$ and $900 \mathrm{rpm}$ ). In addition to engine speed and manifold temperature, Leppard [5] points out that intake manifold pressure also varies because the carburetor used for octane rating has a restrictive throat, resulting in lower manifold pressures at the higher-speed condition of the MON test. Using $\mathrm{CO}$ emissions as an indication of the extent of reaction, he showed the effects of engine speed and manifold pressure on the extent of cool-flame reaction with iso-octane as a function of compression ratio in a motored engine, reproduced here in Figure 1. At a given engine speed, higher manifold pressure increases the extent of the low-temperature reactions; and at a given manifold pressure, higher engine speeds suppress the low-temperature reactions. 


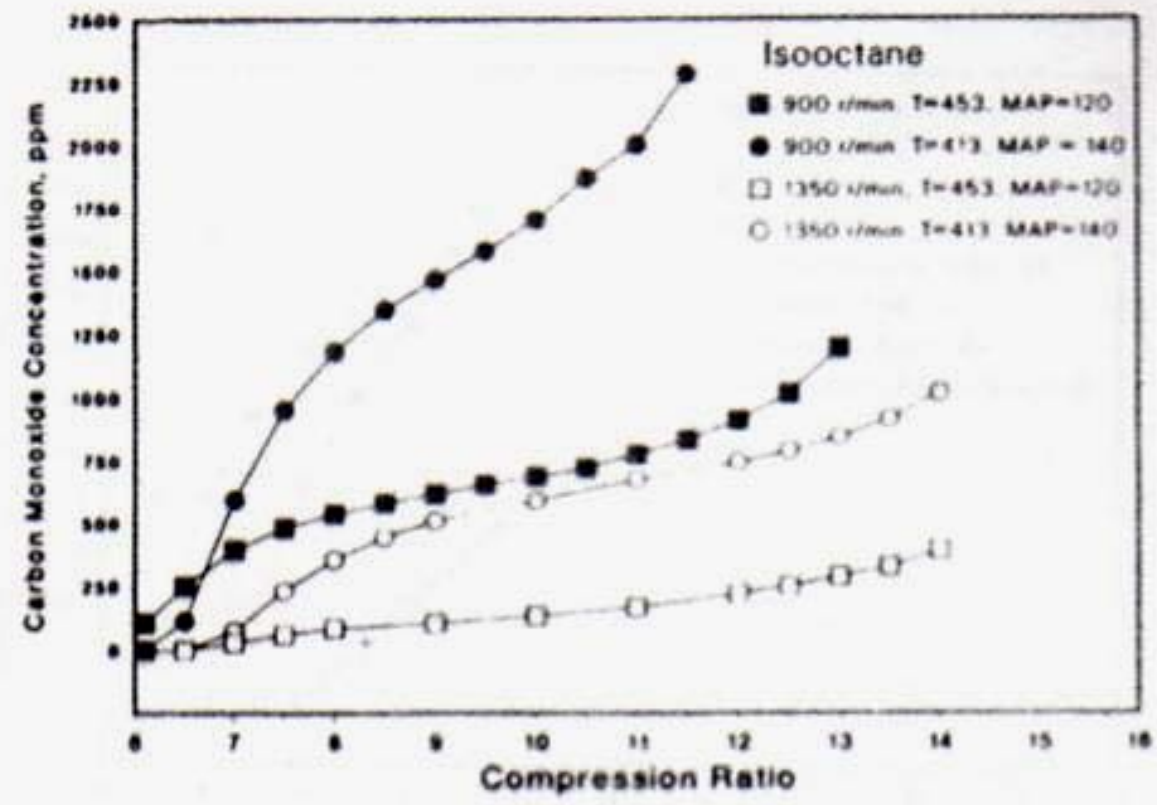

Figure 1. Effects of engine speed and manifold pressure on low-temperature chemistry. Source: Leppard [5].

Paraffinic fuels, which exhibit strong low-temperature heat release, are prone to knocking in the RON test because the engine speed is low and the manifold pressure is near ambient. However, during the MON test, the conditions are less conducive to lowtemperature chemistry because the engine speed is higher and the manifold pressure is sub-ambient, resulting in paraffinic fuels being more resistant to knocking. The knocking resistance of aromatics and olefins is much less dependent on the engine conditions and therefore the fuels have roughly the same knocking tendency at both engine conditions. But because paraffin chemistry is the standard for the octane number scale, olefinic and aromatic fuels have a comparative disadvantage during the MON test and therefore can have significantly lower MONs than RONs. Octane sensitivity (S), shown in Eq. (1), is the difference between RON and MON. Paraffins generally have a low $S$ because paraffinic chemistry is the standard for the octane scale, while aromatics and olefins have a much larger S. Leppard [5] also described this phenomenon on the basis of the NTC regime, not on the basis of low-temperature chemistry, as was discussed here.

$$
S=R O N-M O N
$$

Yates et al. [6] add further questions about the meaning of RON and MON. They note that the ASTM knock meter used in the RON and MON tests correlates to the rise in pressure before knock occurs, and not the fluctuating pressure, or ringing, which is the main characteristic of the knocking event. Fuels with sufficiently high burn rates during SI combustion, such as benzene, can produce high pressure rise rates without knocking, thereby producing a false indication of knocking in both the RON and MON tests. When the knocking tendency of full boiling range (FBR) fuels was measured with an accelerometer and compared with that of a PRF blend with an equivalent RON or MON, 
the octane number ratings of the FBR fuels were found to be very conservative, particularly those high in olefins and aromatics.

Given the above discussion that complicates the meaning and relevance of octane number, it is not surprising that octane numbers of different fuels do not blend linearly. Leppard [7] investigated the blending octane number (BON) of pure components, which is determined by mixing $20 \mathrm{vol} \%$ of the compound of interest with $80 \mathrm{vol} \%$ of PRF 60 . The BON is calculated using Eq. (2) and represents an extrapolation of the hypothetical octane number a pure component would have if its octane number blended linearly with the PRF 60 fuel blend. The BON can represent either the blending RON or MON, depending on which measured octane number is used in Eq. (2).

$$
B O N=60+5 \times(\text { MeasuredON }-60)
$$

It was found that as a class of compounds, only paraffins had BONs similar to their pure component octane numbers. Both olefins and aromatics had BONs that exceeded their pure component octane numbers by as much as 40 octane numbers, or more in some cases. According to Leppard [7], the high BONs indicate that the interactions between the paraffinic constituents of PRF 60 with either olefins or aromatics have the net effect of reducing the reactivity of the mixture. However, given the observations of Yates et al. [6], the high BONs for olefins and aromatics could be a matter of slowing the burning rate of the mixture, resulting in the elimination of the false knock reading that was originally measured. If the latter case is correct, the BON would actually be the more relevant measure of auto-ignition in HCCI engines.

Kalghatgi [8] observed a similar trend with octane numbers, although the results were reported in a different context. The antiknock quality of blends from refinery streams was studied, including streams from the alkylation unit ( $>98 \%$ iso-paraffins), the light catalytic cracking unit ( $\sim 36 \%$ iso-paraffins, $\sim 46 \%$ olefins), and a reformer unit with a platinum-based catalyst $(>71 \%$ aromatic). These refinery streams were blended with each other and with n-heptane and compared with a PRF 85 blend in two different singlecylinder engines. The engines were equipped with custom knock meters, and the tests were performed by advancing the spark timing until the knock intensity reached a predetermined threshold. The spark timing at the threshold was designated as the knock limited spark advance (KLSA). The KLSA was correlated to a novel octane index (OI), shown in Eq. (3), where $K$ is an experimentally determined constant dependent on the pressure-temperature history of the in-cylinder gases. It should be noted that a $K$ value of 0.5 yields an OI equivalent to the mean value of the RON and MON, or the commonly reported octane value. It should also be noted that $K$ is not dependent on the fuel but rather dependent on engine operating conditions.

$$
O I=R O N-K * S
$$

It was found that as engine conditions were made more prone to knocking (i.e., wide open throttle, low engine speed, and high compression ratio) the value of $K$ became negative. So, compared with PRF blends, the refinery streams had a greater resistance to knocking than the RON predicted, and the magnitude of the knocking resistances increased with increased octane sensitivity. Kalghatgi [8] designated the regime where the $K$ value is negative as being "beyond RON" because it represents an area where the 
knocking tendency can no longer be interpolated between RON and MON but rather has to be extrapolated.

Yates et al. [6] further elaborated on the "beyond RON" regime, and clarified its meaning with illustrations, reproduced here in Figure 2. The temperature and pressure lines on these plots correspond to a fixed crank angle ignition delay where the RON test ignition delay is $4.5 \mathrm{~ms}$ and the MON ignition delay is $3 \mathrm{~ms}$. The solid line corresponds to a theoretical auto-ignition line for an FBR fuel, and its characteristic s-shape is caused by the low-temperature chemistry and NTC region. Diagram (a) shows that the KLSA points, over a range of speeds and loads with a carbureted engine, fall between the conditions of the RON and the MON test. However, port fuel injection made high-speed knocking less of a concern. This is because port fuel injection has enabled advances in volumetric efficiency because fuel droplets no longer have to be entrained by the air flow for the relatively long distances required with carburetors. The higher volumetric efficiency results in a higher pressure history in the cylinder, making RON more relevant than MON, even at high engine speeds, as shown in diagram (b). This trend is pushed even further, into the "beyond RON," when the intake pressure is increased with a turbocharger or supercharger.

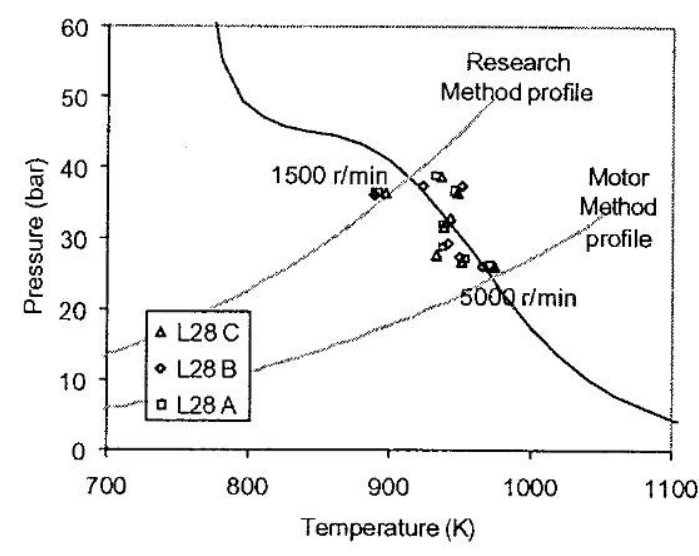

(a)

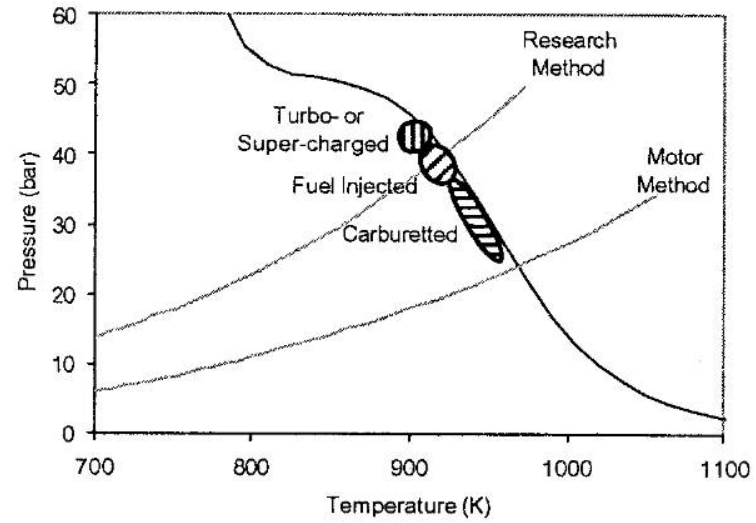

(b)

Figure 2. Auto-ignition profiles of hydrocarbons for (a) carbureted engines at various speeds, and (b) pressure temperature ranges for different engine types. Source: Yates et al. [6].

Thus the findings of Leppard [7], Kalghatgi [8], and Yates et al. [6] all contribute to an overall understanding of the meaning of octane numbers. Leppard [7] found that aromatics and olefins, both of which have high octane sensitivities, blend in highly nonlinear ways with regard to octane number, resulting in higher than expected octane numbers. Kalghatgi [8] found that fuels with high octane sensitivities resist knock better than even the RON predicts, especially at engine conditions where a PRF fuel blend is prone to knock, an operating regime described as being "beyond RON". And Yates et al. [6] explains that the "beyond RON" regime is relevant even at high speeds because of volumetric efficiency advances enabled by port fuel injection. Thus, many gasolines have octane numbers that are rated conservatively; and in many cases, a greater octane sensitivity provides an increased resistance to auto-ignition compared with what the octane number predicts. 


\subsection{Auto-ignition Behavior of Hydrocarbons}

Tanaka et al. studied the ignition behaviors of different classes of hydrocarbons in a rapid compression machine (RCM) [9]. The classes of fuels included n-paraffins (nheptane), iso-paraffins (iso-octane), cycloparaffins (cyclohexane and methylcyclohexane), n-olefins (1-heptene, 2-heptene, and 3-heptene), cyclo-olefins (cyclohexene and 1,3-cyclohexadiene), and aromatics (toluene). All of the paraffins, 1heptene, and 2-heptene displayed two-stage ignition, while 1,3-cyclohexadiene, cyclohexene, and 3-heptane exhibited only 1-stage ignition. Toluene did not ignite in this study. The ignition behaviors of these fuels are shown in Figure 3.
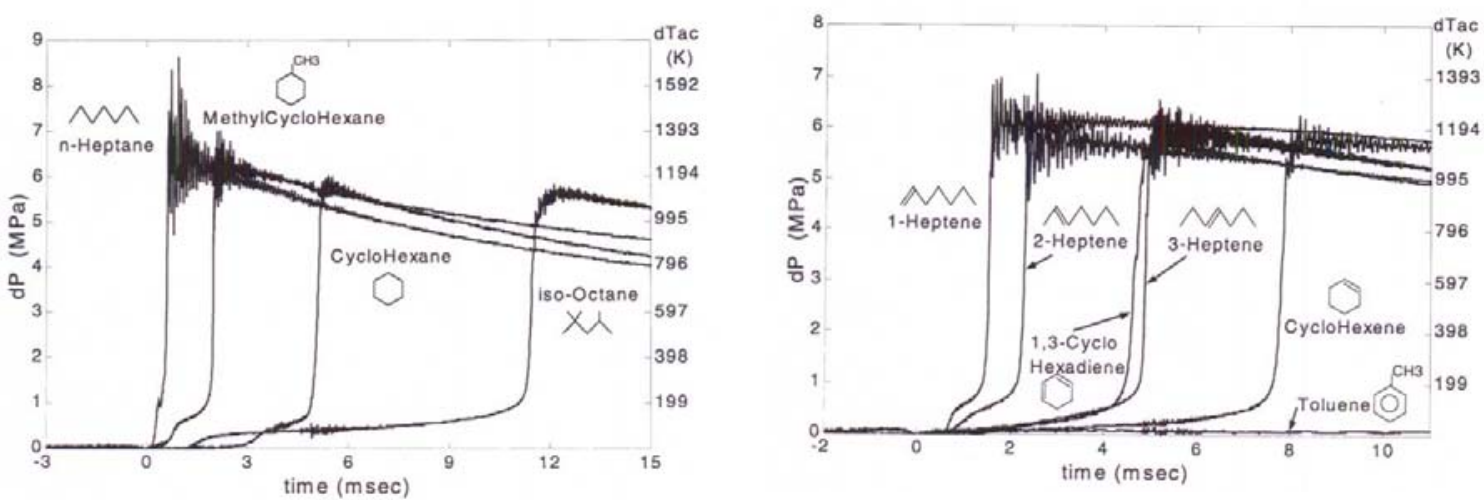

Figure 3. Auto-ignition behaviors of various fuels in a rapid compression machine. Source: Tanaka et al. [9].

It is interesting to note that, for 1-heptene and 2-heptene, the double bond is not the dominant feature of the molecule, so they continue to exhibit strong low-temperature ignition. However, if the double bond is in the middle of the molecule, as with 3-heptene, the alkyl groups are too short to participate in the low-temperature chemistry and do not exhibit two-stage ignition. It is also interesting to note that the presence of two-stage ignition does not necessarily reduce the ignition delay, as is evidenced by the fact that the ignition delay of iso-octane is longer than that of 1,3-cyclodiene, 3-heptene, and cyclohexene.

Andrae et al. [10] modeled the effects of $n$-heptane interacting with blends of isooctane or toluene during auto-ignition. In order to be able to match experimental results, the radicals formed from one type of molecule interacting with the other molecule had to be taken into account. For instance, the radical pool that is formed by the lowtemperature oxidation of n-heptane prefers to extract a hydrogen atom from the methyl group on the toluene rather than from n-heptane because the hydrogens on the toluene methyl group have lower bond dissociation energies. This effect results in inhibiting nheptane oxidation and produces more benzyl radicals, which are less reactive than heptyl radicals.

Shibata et al. [11] studied the behaviors of different fuel types by blending 11 pure components into model fuels for HCCI operation. The 11 fuels included n-paraffins (n-pentane, n-hexane, n-heptane), iso-paraffins (2-methylpentane, iso-octane), olefins (4methyl-1-pentene, diisobutylene), naphthenes (cyclopentane, cyclohexane), and aromatics (toluene, m-xylene). The researchers found that the magnitude of the energy 
released during low-temperature reactions directly affected the phasing of the main combustion event in HCCI mode. They also found that n-paraffins contributed the most to low-temperature energy release, followed by iso-paraffins, olefins, and naphthenes and aromatics last. The olefins used in this study are both branched, so it is not surprising that they do not contribute as much to low-temperature heat release as 1-heptene and 2heptene did in the study by Tanaka et al. [9], shown in Figure 3. However, the observation of low-temperature heat release for naphthenes in this study seems to be inconsistent with Tanaka et al. [9]. That team found that aromatics not only did not contribute to low-temperature heat release but also actually suppressed the lowtemperature heat release of the other constituents in the fuel blend.

Thus, the findings of Tanaka et al. [9] show that while classifying hydrocarbons into n-paraffins, iso-paraffins, olefins, and aromatics can be helpful when describing auto-ignition behavior, it is not a complete description. For instance, the three isomers of heptene had very different auto-ignition behavior, depending on where the double bond was located in the molecule. Tanaka et al. [9] also found that the amount of heat released during low-temperature chemistry was not necessarily a predictor of when main ignition would occur in the RCM; whereas Shibata et al. [11] did find that the amount of heat released during the cool flame, regardless of the fuel, directly impacted the phasing of combustion in an HCCI engine. In addition, Shibata et al. [11] and Andrae et al. [10] both found that the magnitude of the low-temperature heat release could not be described by a weighted average of the components in the fuel mixture. Instead, Andrae et al. [10] found that interactions of radicals had to be taken into consideration, and Shibata et al. [11] found that interactions of radicals can lead to a suppressed heat release.

\subsection{Octane Number and HCCI}

The previous sections show that RON and MON are not necessarily predictive of the occurrence of knocking with FBR fuels. They also established that under the conditions of modern SI engines, RON is more relevant; and because of the chemistry differences, a high $S$ may actually enhance the ability of a fuel to resist knock. However, the auto-ignition behavior of a fuel blend cannot be described as the sum of the parts of that blend. The extent to which RON and MON are applicable to describing the behavior of fuel in HCCI engines is unclear. This section discusses several HCCI studies that analyze different gasoline-type fuels.

Duret [12] studied the auto-ignition ranges of gasoline-type fuels in a two-stroke 250-cc engine and defined a controlled auto-ignition (CAI) number. The operable speed and load range was investigated for each fuel, and the resulting CAI number is an index of the operable range of the given fuel compared with that of a reference fuel. A high CAI number corresponds to a wide operating range, and a low CAI number corresponds to a small operating range. The CAI number was compared with both the RON and MON and is shown in Figure 4. A high CAI number could be obtained by fuels with both high and low RON and MON values. Duret concluded that there was no direct correlation between either RON or MON and the CAI number. No information was given about the chemical compositions of the fuels tested for the CAI number correlation. 

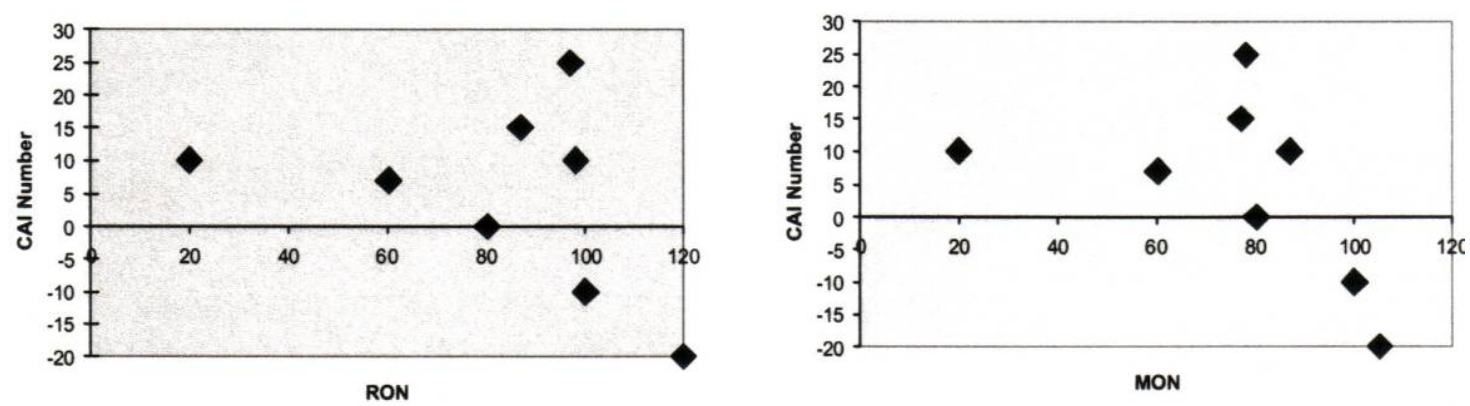

Figure 4. Comparison of RON and MON to CAI number. Source: Duret [12].

Aroonsrisopon et al. investigated the effects of fuel composition on HCCI performance [13]. A CFR (Cooperative Fuel Research) octane rating engine at a constant compression ratio of 16.55 was operated at three different intake charge temperatures: 340,360 , and $380 \mathrm{~K}$. The operable speed and load range was constrained by a knocking limit (a maximum of $10 \mathrm{bar} / \mathrm{deg}$ pressure rise rate) and a misfire limit. The fuels investigated included n-butane, PRF 91.8, PRF 70, and two different indolenes blended with n-heptane to reduce the RON (BIN-1 and BIN-2). The specifications of these fuels are given in Table 3.

Table 3. Select properties of tested gasolines. Source: Aroonsrisopon et al. [13]

\begin{tabular}{|c|c|c|c|c|}
\hline Fuel & RON & MON & $S$ & Aromatics \\
\hline n-Butane & 91.8 & 89.0 & 2.8 & 0 \\
\hline PRF 91.8 & 91.8 & 91.8 & 0 & 0 \\
\hline BIN-1 & 94.1 & 86.8 & 7.3 & 35.08 \\
\hline BIN-2 & 93.0 & 86.2 & 6.8 & 31.32 \\
\hline PRF 70 & 70.0 & 70.0 & 0 & 0 \\
\hline
\end{tabular}

The ranges of speed and load operability of the fuels at each temperature are given in Figure 5. PRF 70 was not run at $380 \mathrm{~K}$ because of the knocking limit, and BIN-1 was not run at $340 \mathrm{~K}$ because of the misfire limit. It is apparent that for the four highoctane fuels, each has a unique range of operability. For instance, at the highest intake temperature at high speeds, BIN-2 has the leanest operating range, followed by BIN-1 and n-butane, with PRF 91.8 requiring the richest conditions. It appears that neither RON, MON, nor $S$ can satisfactorily explain these trends.
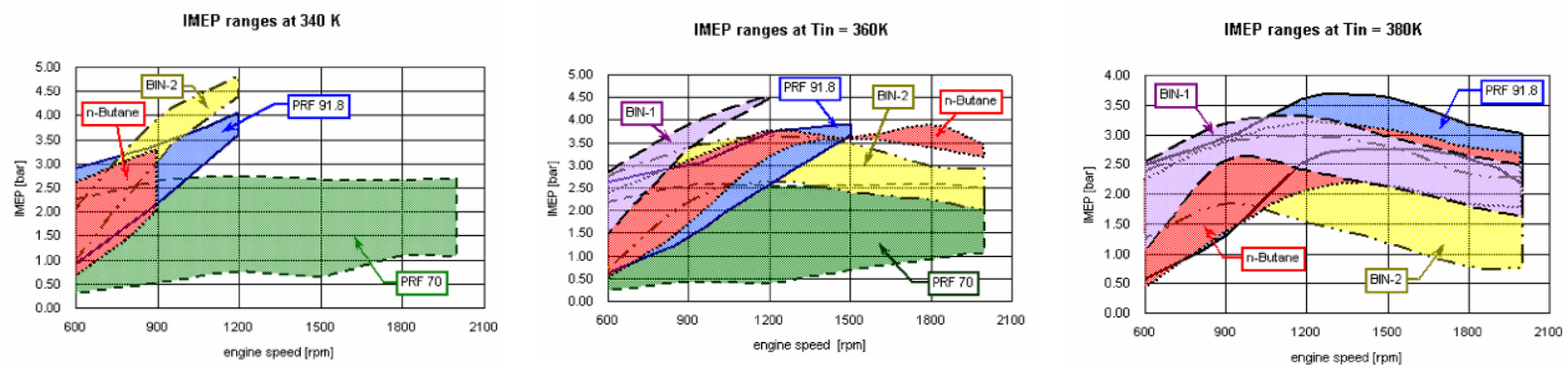

Figure 5. Operating ranges of different fuels at various intake temperatures. Source: Aroonsrisopon et al. [13]. 
The effect of engine speed was also investigated by Aroonsrisopon and coworkers [13], and the pressure and heat release for the high-octane fuels are shown in Figure 6 at $600 \mathrm{rpm}$ and $1800 \mathrm{rpm}$. At the 600-rpm condition, n-butane ignition occured earliest, followed by BIN-2 and BIN-1. However, at $1800 \mathrm{rpm}$, the ignition of BIN-2 occured at the earliest timing, followed by BIN-1, and n-butane had the latest timing. This complete reversal in ignition phasing for $n$-butane can be explained through the low-temperature chemistry discussed earlier in Section 2.1. At the low-speed condition, which is the condition that is more prone to engine knocking, more time is available for the lowtemperature chemistry to take place. Although the low-temperature heat release is too low to produce a noticeable cool flame on the heat release profile, it does release enough energy to advance the ignition timing for that fuel. At the higher-speed condition, less time is available; the reduced time reduces the low-temperature heat release, producing a retarded ignition timing by comparison. This trend is in agreement with the work of Leppard [5], shown in Figure 1, which predicts the behavior seen here.
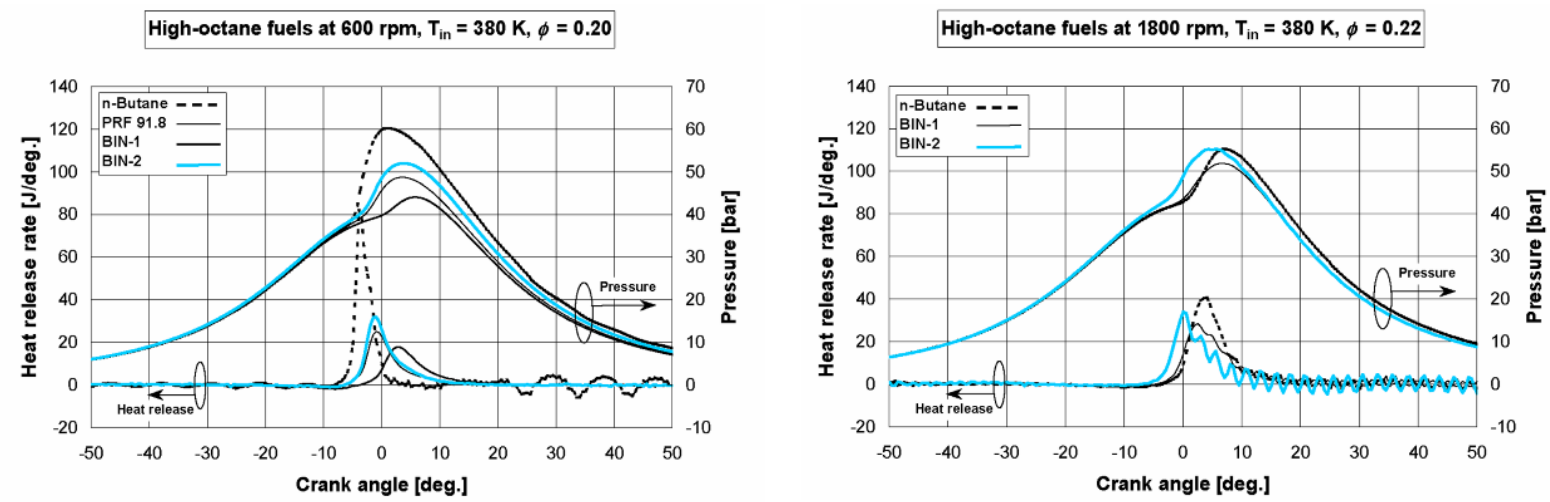

Figure 6. Effects of engine speed for different fuel types of similar octane number. Source: Aroonsrisopon et al. [13].

Christensen et al. [14] investigated the behavior of different fuel blends in an HCCI engine in two ways: with PRF mixtures and blending conventional gasoline with conventional diesel fuel. The intake air temperature $\left(30\right.$ to $\left.130^{\circ} \mathrm{C}\right)$ and compression ratio (10:1 to 28:1) were used to control the phasing of HCCI ignition close to TDC. Christensen's team were able to operate all of the fuels in HCCI mode, although the higher-octane-number blends required a higher compression ratio at a given temperature, or a higher intake temperature at a given compression ratio. The low-octane-number PRF blends and the gasoline/diesel blends that were high in diesel concentration exhibited a significant cool flame heat release. It was also observed that the higher-octane-number fuel blends had a higher indicated thermal efficiency even though their combustion efficiency was comparable to or lower than the combustion efficiency of the loweroctane-number fuel blends. A significant difference in the indicated thermal efficiency between the PRF blends and the gasoline/diesel blends was observed. The thermal efficiency of the PRF blends dropped rapidly with decreasing compression ratio; but the thermal efficiency of the gasoline/diesel blends was less sensitive to compression ratio, although the PRF blends had the highest maximum thermal efficiency.

A series of studies were performed to extend the relevance of octane index, as defined by Kalghatgi [8], to HCCI engines [15-18], culminating in a recent review [19]. In these studies, an $\mathrm{OI}_{\mathrm{o}}$ was defined as the $\mathrm{OI}$ required by the engine for $50 \%$ of the mass 
fraction of the fuel (MFB 50) to be consumed at TDC. For each operating condition, there is a fuel with an OI [as defined by Eq. (3)] equivalent to $\mathrm{OI}_{0}$ where MFB 50 will occur at TDC. However, just as OI is dependent on the engine operating conditions through the $K$ term in Eq. (3), $\mathrm{OI}_{\mathrm{o}}$ is also dependent on engine operating conditions.

Yates et al. [6] showed in Figure 2 that modern SI engines are moving further into the "beyond RON" operating regime, resulting in a negative $K$ value when the OI is calculated in Eq. (3). However, Kalghatgi [19] shows that a much wider range of $K$ value is applicable to HCCI engines, $-2<K<5$. The $K$ value was found to largely depend on the cylinder temperature that occurs at a compressive pressure of $15 \mathrm{bar}\left(\mathrm{T}_{\text {comp15 }}\right)$, and to a lesser extent, $\lambda$. The relationship between $K$ and $T_{\text {comp15 }}$ is shown in Figure 7 for fuels with RON from 60 to $95.7, S$ from 0 to 12.4 , aromatics as high as $64 \%$ in blends of toluene and n-heptane and $28.5 \%$ in FBR fuels, olefins as high as $40 \%$, and ethanol as high as $20 \%$. These data points were taken at engine conditions ranging in speed from 900 to $3000 \mathrm{rpm}$, and for $\lambda$ from 5 to 2.5. Despite the wide variation in fuel composition and in operating conditions, very little scatter is seen in the relationship between $K$ and $T_{\text {comp15. }}$ Two empirical relationships for $K$ were developed, one for $T_{\text {comp15 }}<825 \mathrm{~K}$ and one for $T_{\text {comp15 }}>825 \mathrm{~K}$; they are given in (4) and (5), respectively.

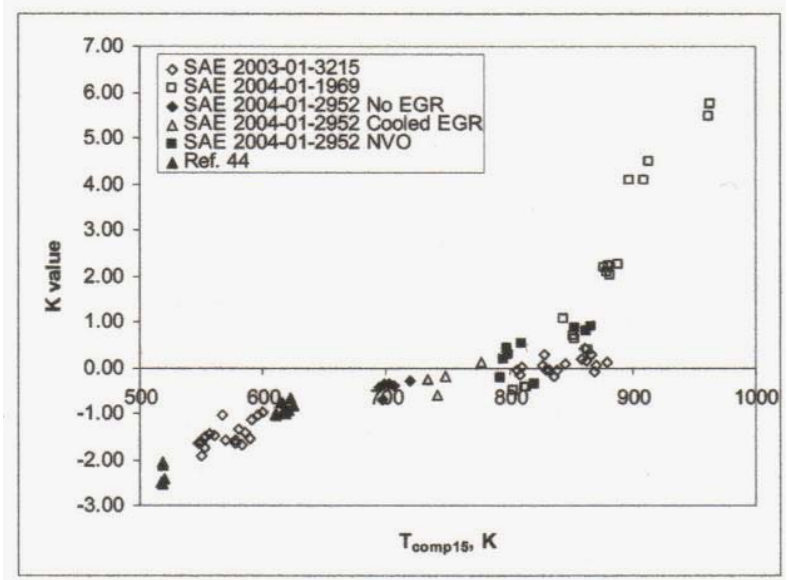

Figure 7. $\mathrm{K}$ value for $\mathrm{OI}$ calculation as a function of $T_{\text {comp15 }}$ for a variety of different fuel compositions and engine operating conditions. Source: Kalghatgi [19].

$$
\begin{array}{ll}
T_{\text {comp } 15}<825 \mathrm{~K} & \mathrm{~K}=0.00497 *\left(T_{\text {comp } 15}\right)-0.135 * \lambda-3.67 \\
T_{\text {comp } 15}>825 \mathrm{~K} & \mathrm{~K}=0.0426 *(\text { Tcomp15 })-32.5
\end{array}
$$

Kalghatgi [19] also developed an empirical relationship between $\mathrm{OI}_{\mathrm{o}}$ and the engine operating conditions, given in (6), where $T_{\text {maxcomp }}(\mathrm{K})$ and $P_{\text {maxcomp }}$ (bar) are the maximum compressive temperatures and pressures; $\lambda^{*}$ is a $\lambda$ value that has been normalized for EGR, given in (7); and $N$ is the engine speed in rpm. A good relationship can be seen between the calculated $\mathrm{OI}_{\mathrm{o}}$ and measured $\mathrm{OI}_{0}$, shown in Figure 8, with only a small number of outliers. 


$$
\begin{aligned}
& \mathrm{OI}_{\mathrm{o}}=59+0.015 * T_{\text {compmax }}+0.66 * P_{\text {compmax }}-2.6 \lambda *-0.0123 * N \\
& \lambda^{*}=\left(1+\mathrm{EGR}_{\mathrm{f}}\right) * \lambda
\end{aligned}
$$

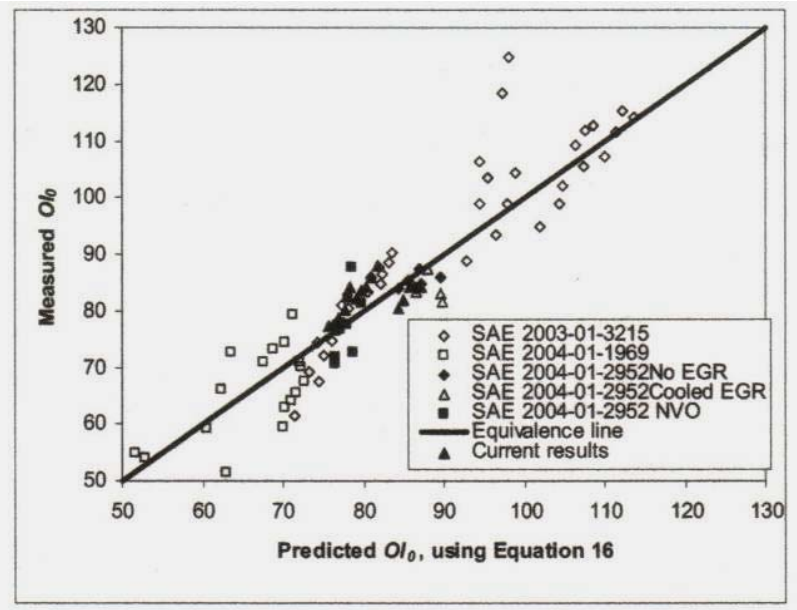

Figure 8. Comparison of calculated and measured $\mathrm{OI}_{\mathbf{0}}$. Source: Kalghatgi [19].

Kalghatgi [19] continues that ideally, the OI of the fuel would match the $\mathrm{OI}_{\mathrm{o}}$ required by the engine at all operating conditions; but in reality, that ability is limited. For $\mathrm{OI}>\mathrm{OI}_{0}$, the MFB 50 timing will be later than TDC; and if retarded far enough, it will result in misfire. For $\mathrm{OI}<\mathrm{OI}_{0}$, the MFB 50 timing will occur earlier than TDC, resulting in higher pressure rise rates and knock. Fuels with high $S$ have a comparative advantage over fuels that have low $S$ because OI changes in the same direction as $\mathrm{OI}_{\mathrm{o}}$ as pressure and temperature in the engine change, whereas fuels with $S=0$ have a constant OI at all operating conditions.

\section{FUEL VOLATILITY}

An HCCI engine for vehicle use must have a compact fueling system that is capable of rapid transients in the quantity of fuel delivered into the cylinder. This makes many of the research fueling systems impractical for vehicles, such as the one used by Aroonsrisopon [13] where the fuel injector is upstream of a large surge tank. Because of this, port fuel injection or early direct injection, based on either diesel fuel injection equipment or gasoline direct injection equipment, is of interest. With either port or direct fuel injection, measures must be taken to ensure good mixing of the fuel and air. Incylinder fluid dynamics is one way to impact this process, but so is the volatility of the fuel.

Oakley et al. [20] distilled a standard gasoline into its light components and its heavy components. The properties of the two fuel cuts, as well as the starting fuel, which are given in Table 4, show that the lighter of the two cuts is comparatively high in paraffins and low in aromatics. These fuels were investigated under HCCI conditions at $1500 \mathrm{rpm}$ with a compression ratio of 11.5 using port fuel injection. The operable engine load range at this speed was explored by varying EGR and fueling rate and is shown in Figure 9. Oakley et al. found no significant differences in either the operating range or 
combustion phasing between the three different fuel blends. They concluded that octane number is not an predictor for auto-ignition applications and that increasing either the paraffinic or aromatic content will not have a significant effect on the operable speed/load range [20].

Table 4. Fuel properties of distilled BP gasoline. Source: Oakley and coworkers [20]

\begin{tabular}{|c|c|c|c|c|}
\hline 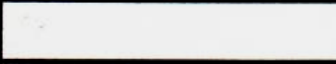 & \begin{tabular}{|c|} 
Type 1 \\
Distilled from Type $2\left(\right.$ (IBP* $\left.-90^{\circ} \mathrm{C}\right)$
\end{tabular} & \multicolumn{2}{|c|}{$\begin{array}{c}\text { Type 2 } \\
\text { BP Premium Unleaded Gasoline }\end{array}$} & \begin{tabular}{|c|} 
Type 3 \\
Distilled from Type $2\left(90^{\circ} \mathrm{C}\right.$ - FBP*)
\end{tabular} \\
\hline & & \multicolumn{2}{|c|}{ BS EN 228 Marketing Specification } & \\
\hline & & MIN & MAX & \\
\hline Aromatics & 15.5 & \multicolumn{2}{|c|}{34.1} & 47.5 \\
\hline Paraffins & 72.1 & \multicolumn{2}{|c|}{58.3} & 42.6 \\
\hline Olefins & 12.4 & \multicolumn{2}{|c|}{7.6} & 9.9 \\
\hline Research Octane Number (RON) & 93.5 & 95 & & 98 \\
\hline Motor Octane Number (MON) & 85 & 85 & & 86.5 \\
\hline Fuel Sensitivity (RON-MON) & 8.5 & \multicolumn{2}{|c|}{10} & 11.5 \\
\hline Total lead $(\mathrm{g} / \mathrm{l})$ & & & 0.013 & \\
\hline Total Sulphur (\%m/m) & 0.01 & & 0.05 & 0.04 \\
\hline Density $15^{\circ} \mathrm{C}\left(\mathrm{kg} / \mathrm{m}^{3}\right)$ & & 725 & 780 & - \\
\hline Vapour Pressure (kPa) & & 45 & 80 & \\
\hline
\end{tabular}
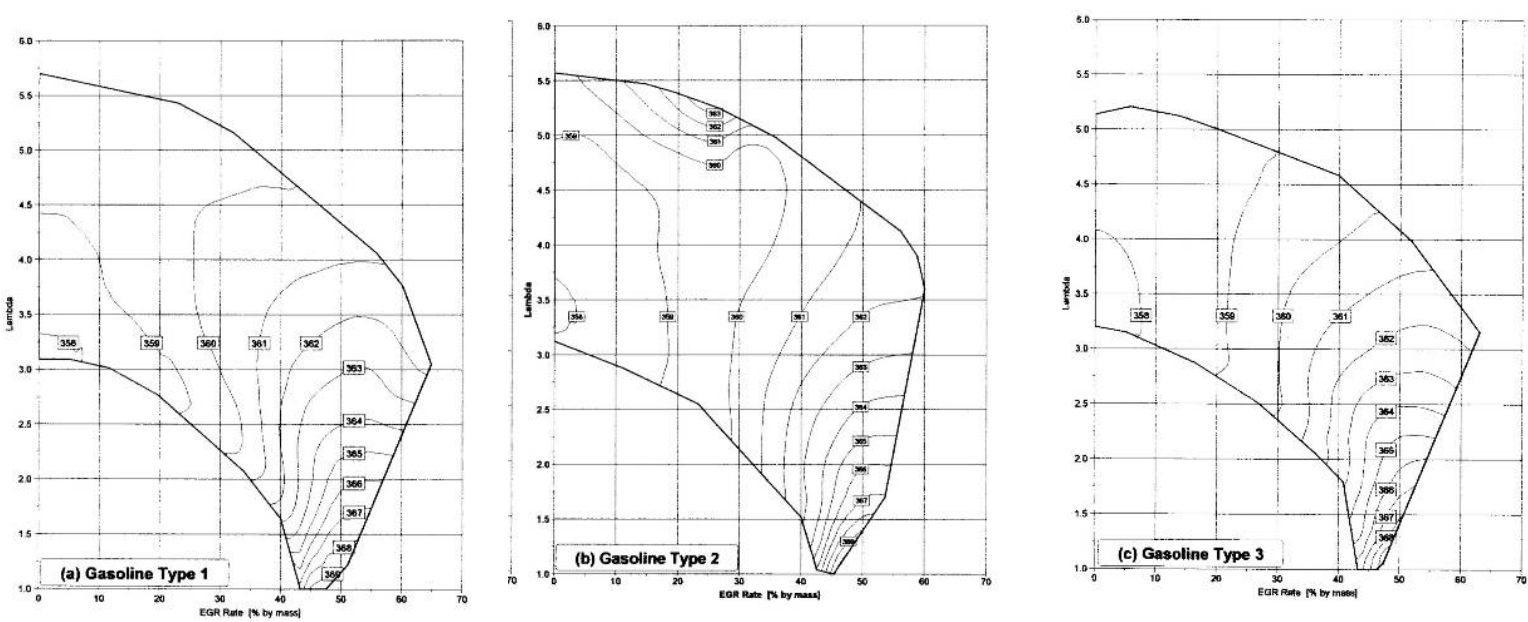

Figure 9. Operating ranges for FBR gasoline and light and heavy cuts, with contour lines representing $10 \%$ mass fraction burned. Source: Oakely et al. [20].

Collin and coworkers [21] studied the effects of fuel volatility in an optically accessible HCCI engine using planar laser-induced fluorescence (PLIF) to identify the timing and concentration of formaldehyde and hydroxyl radicals. The direct injection engine was operated at $1200 \mathrm{rpm}$ while the start of injection (SOI) was varied. n-Decane was used as the low-volatile fuel and PRF 50 was the high-volatile fuel. Neither of these fuels has a gasoline-like octane number, but they are relevant to gasoline HCCI from a fuel and air mixing standpoint. PLIF images taken at $14^{\circ}$ before TDC were analyzed for the homogeneity of formaldehyde and for the fraction of surface area on the PLIF image where a formaldehyde signal was present. Figure 10, taken from Collin et al. [21], shows the homogeneity index and surface fraction as functions of the start of injection, as well as the NOx emissions. 


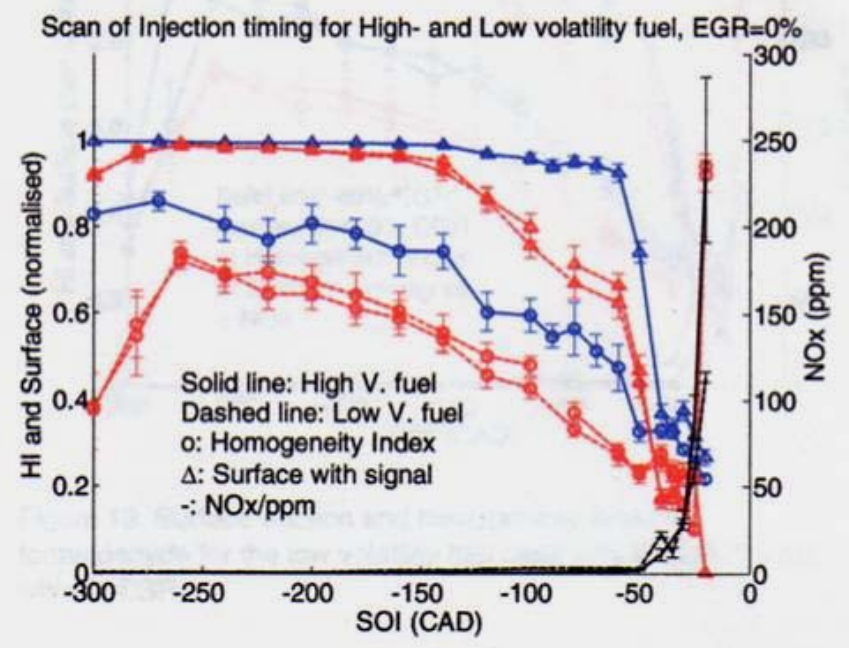

Figure 10. Surface fraction and homogeneity index of formaldehyde and NOx emissions for high- and lowvolatility fuels as functions of SOI timing, all data collected at $14^{\circ}$ before TDC. Source: Collin et al. [21].

For both fuels, the homogeneity index and the formaldehyde signal surface fraction decreased as the SOI timing was delayed. Delaying the SOI timing also had the effect of delaying the phasing of the combustion event. The high-volatility fuel was found to be more homogenous at all SOI timings than the low-volatility fuel. This result also shows that the homogeneity of formaldehyde, which is taken to be proportional to the homogeneity of the fuel concentration, can be relatively low at the start of ignition and still produce low NOx emissions. The NOx emissions increased dramatically when the SOI timing was retarded past $50^{\circ}$ before TDC, and there was no significant difference between the fuels.

Thus, fuel volatility affects the mixing of the fuel and air in HCCI engines. Collin et al. [21] clearly showed that more volatile fuels produce a more homogeneous charge and ignition process at all SOI timings. Retarding the SOI timing caused the mixing to become less homogeneous for both fuel types, and it had the effect of retarding the combustion phasing. The less homogeneous fuel and air charge did not result in high NOx emissions until the fuel injection timing was retarded past a threshold SOI timing of $50^{\circ}$ before TDC. The observations of Oakely et al. [20], who distilled a gasoline into its light components and heavy components, were very similar. Using port fuel injection for the three different gasoline blends, they observed no significant performance differences between the three fuels. So even though fuel volatility affects mixing, the fuel and air charge does not have to be homogeneous to achieve good emissions and performance, and satisfactory mixing could be achieved by advancing SOI timing. It should be noted that both of these studies used relatively slow engine speeds (1200 rpm and $1500 \mathrm{rpm}$ for Collin et al. [21] and Oakely et al. [20], respectively). It is unclear if the mixing effects can be overcome as easily at higher engine speeds when less time is available for mixing.

The authors of this review would like to point out that we disagree with the conclusion from Oakley et al. [20] that the operable speed/load range was independent of 
aromatic and paraffin content. In our opinion, coming to this conclusion after testing at one engine speed, $1500 \mathrm{rpm}$, is premature. As was discussed in Section 2.2, Leppard [5] showed that engine speed can have a significant effect on the extent of the cool-flame chemistry of paraffins, which has a significant impact on combustion phasing. Thus, simply that all of the fuels had similar ignition phasing at $1500 \mathrm{rpm}$ does not mean that they will be similar over the entire speed range.

\section{ALCOHOL FUELS}

Oakley et al. [20] studied the effects of ethanol and methanol on the HCCI operating range while EGR was used to control combustion. The operating ranges for methanol and ethanol, compared with the operating range for gasoline, are shown in Figure 11. Using ethanol, the low-load operating range was expanded compared with conventional gasoline; and using methanol, the operating range was expanded even further. Ethanol and methanol were also much more tolerant of high EGR rates, over $70 \%$, whereas gasoline is able to tolerate only about $60 \%$ EGR. The authors attributed this difference to the ignition phasing of the alcohol fuels being relatively independent of the EGR rate, allowing the EGR rate to be increased further.
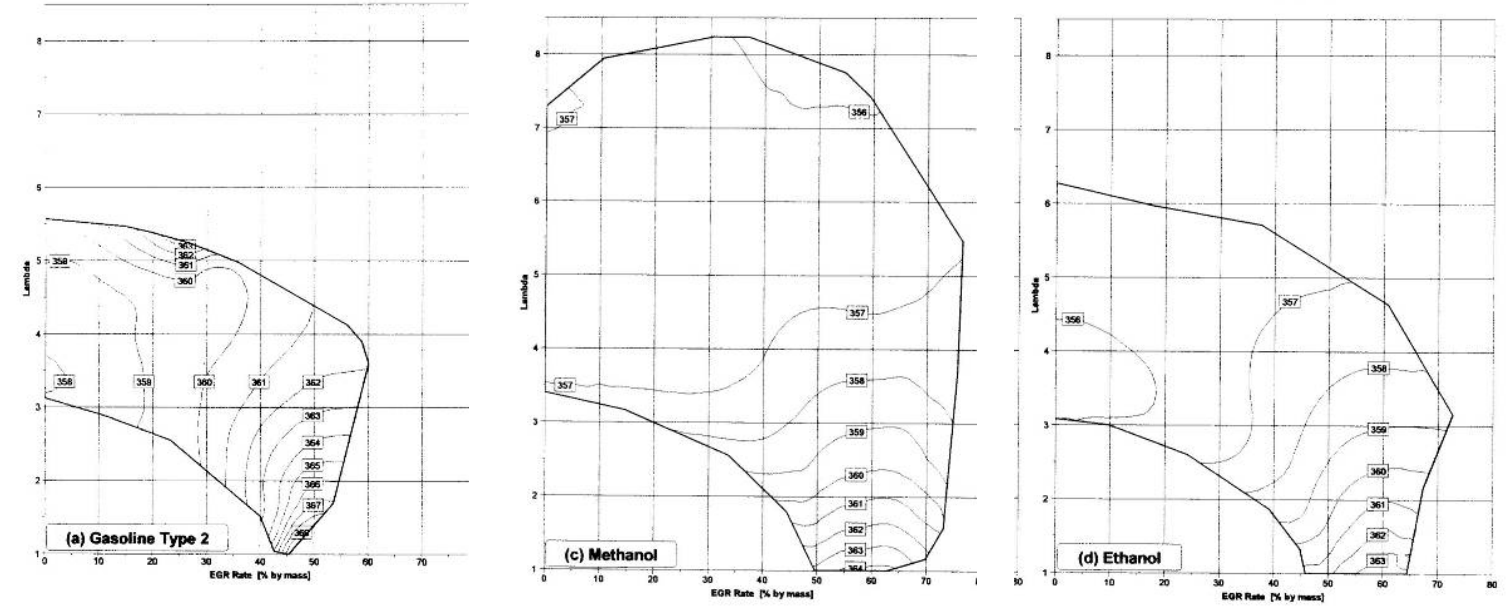

Figure 11. Operable ranges for gasoline, methanol, and ethanol at $1500 \mathrm{rpm}$ with contour lines representing $10 \%$ mass fraction burned. Source: Oakley et al. [20].

Christensen et al. studied the effects of ethanol in HCCI and compared them with the results for iso-octane under both naturally aspirated conditions and supercharged conditions. They found that during naturally aspirated operation, ethanol was able to operate at leaner conditions than iso-octane. However, when the engine was operating under supercharged conditions, the indicated mean effective pressure of ethanol increased compared with iso-octane, even though they were operating at the lambda value. So at naturally aspirated conditions, ethanol was able to extend the operating range to lower load compared with iso-octane; and during supercharged conditions, ethanol was able to increase the operable load range compared with iso-octane [22].

Both Oakley et al. [20] and Christensen et al. [22] observed that ethanol had the ability to expand the range of operation. Oakley et al. [20] showed that the low-load 
operating range could be expanded with ethanol. The findings of Christensen et al. [22] agreed that the low-load operating range could be expanded with ethanol under naturally aspirated conditions and added that the high-load operating range could be increased under supercharged conditions. In comparing methanol and ethanol, Oakley et al. showed that larger gains in the operable HCCI range could be made with methanol instead of ethanol. Both of these studies used pure ethanol, and it is unclear if blending ethanol into a standard gasoline would result in similar increases in operable load range.

\section{CONCLUSIONS}

The effect of fuel volatility is primarily an effect on the fuel and air mixing. Increasing fuel volatility will produce a more homogeneous mixture with the air. However, a truly homogeneous mixture is not necessary for good performance in an HCCI engine; and the effects of fuel volatility can largely be overcome by, for example, using a strategy such as advanced fuel injection. Also, although the reasons for the differences between alcohol fuels and hydrocarbons are not fully understood, alcohol fuels have the effect of expanding the operable range during HCCI operation.

The effects of different hydrocarbon components are not as well understood. HCCI engines have different fuel auto-ignition requirements from SI engines, which require only that auto-ignition be avoided to ensure good engine performance. Thus, it is not problematic for SI engines to use fuels with conservatively rated octane numbers and not necessary to accurately predict the conditions at which knock will actually occur, so long as knock doesn't occur. The conservative octane number ratings are partially due to the way that the ASTM knock meter measures knock [6] and partially due to lowtemperature chemistry differences between the PRF fuel blends and FBR fuels that have significant olefinic and aromatic concentrations [7,8]. These are the same chemistry differences that are responsible for differences in RON and MON in FBR fuels.

In HCCI engine operation, however, a conservatively rated index of auto-ignition will result in engine misfire, so a better understanding of the auto-ignition conditions is needed. Trends in hydrocarbon auto-ignition are generally well-understood. n-Paraffins and iso-paraffins both participate in low-temperature chemistry and auto-ignite easily, although low manifold pressure and high engine speed reduces the extent of lowtemperature reactions [5]. Iso-paraffins participate in the low-temperature reactions to a lesser extent because of steric hinderances, so they are more resistant to auto-ignition. Olefins and aromatics participate in low-temperature reactions only if an alkyl group on the molecule is long enough to participate in the internal isomerization reactions; otherwise they are more resistant to auto-ignition than paraffins. The auto-ignition behavior of a fuel cannot simply be described as the sum of the parts of the fuel. Radicals formed during the low-temperature oxidation of n-heptane can be consumed by toluene because of the lower bond-dissociation energy and more stable radical, suppressing further n-heptane oxidation [10]. This inhibiting effect on the low-temperature reactions can shift the expected combustion phasing during HCCI operation [11].

Thus, while simply using RON or MON to describe auto-ignition behavior in an HCCI engine is not sufficient, the parameters that would sufficiently describe a fuel's behavior under HCCI conditions are unclear. It is not enough to make an assessment of fuel in HCCI operation that is relevant to gasoline simply using one or two molecules that 
fall into the categories of $n$-paraffinic, iso-paraffinic, olefinic, and aromatic. Although these categories can describe general trends, not all fuels in a given category behave in the same way, as was seen with the auto-ignition differences between 1-heptene, 2heptene, and 3-heptene [9]. In addition, when only model compounds are used, fuel interactions during the auto-ignition process can easily be neglected.

Kalghatgi [19] established a relationship between the properties of gasoline-like fuels and performance in HCCI operation. There are two sides of the relationship: a prediction of the ignition behavior of the fuel, OI, and a required ignition behavior from the engine, $\mathrm{OI}_{0}$. Both of these correlations are dependent on engine performance, with $\mathrm{OI}$ dependent on RON, $S, T_{\text {comp } 15}$, and $\lambda$, and $\mathrm{OI}_{\mathrm{o}}$ dependent on $T_{\text {compmax }}, P_{\text {compmax }}$, EGR rate, $\lambda$, and engine speed. The relationships developed by Kalghatgi appear to be applicable to gasoline blended from a small number of pure components and to FBR fuels.

Although Kalghatgi [19] demonstrated that the relationships of OI and $\mathrm{OI}_{0}$ are applicable over a wide operating range, there remains a gap of understanding about the direct impact of fuel composition. Refinery operators have a good understanding about how to control the RON of different refinery streams through process control, but they lack the ability to control MON to the same degree with similar techniques [23]. Thus it is important from the point of view of refineries to expand the correlations to HCCI performance beyond OI and to have a direct understanding of how fuel chemistry impacts HCCI.

Thus, while some questions remain about the effects of fuel volatility and the effects of oxygenates, many questions remain unanswered about the behavior of different types of hydrocarbons in HCCI. The types of hydrocarbons that are most important to gasoline are n-paraffins, iso-paraffins, olefins, and aromatics. The relative effects of the gasoline-relevant components in each of these classes can be determined by blending the refinery blending streams that are rich in each of these, i.e. straight-run gasoline, alkylate, catalytic cracking gasoline, and reformate, respectively. Although including pure component blends would have the effect of expanding the possible chemistry differences, these four streams encompass the majority of the chemistry differences available from the gasoline blending components. We recommend that the blends be formulated in a way to maximize the chemistry differences in the fuel blends while holding RON constant, so that a gasoline-relevant basis of comparison is maintained. We also recommend that the selected fuel blends be fully characterized with respect to chemistry in order to allow comparison of results with other studies conducted with blends of pure compounds.

\section{FUEL PROPERTY MATRIX RECOMMENDATIONS}

The following conclusions from the literature search for fuel effects on gasoline HCCI are relevant to designing a fuels matrix for the Coordinating Research Council (CRC) fuels study. In addition, guidance from the CRC committee has also been included.

Fuel chemistry, especially normal paraffins and ratios of iso-paraffins to aromatics and olefins as octane components, affects both the octane ratings and octane sensitivity of blended fuels. Paraffins, especially normal paraffins, possess a unique lowtemperature chemistry that can lead to knock in SI engines and can assist ignition in HCCI engines. Aromatics and many olefins do not possess this low-temperature 
chemistry, are often rated conservatively in octane tests, and can inhibit knock in SI engines to a greater extent that their octane numbers suggest. In HCCI, we wish to enhance the pre-flame reactions of the fuel in order to ensure ignition while allowing control of combustion phasing and rate of burning over a wide range of speeds and loads. The relationship of these characteristics to fuel chemistry and existing octane ratings is not well understood and is also dependent on operating condition and engine design. Fuels exhibiting high octane sensitivity (aromatic or olefin derived) are expected to behave differently from fuels with low octane sensitivity (paraffin derived). Refineries today are optimized to produce high-octane components for SI gasoline (aromatic, isoparaffin, olefin) while minimizing low-octane components (normal paraffin). Fuel volatility in the normal range for gasoline is not expected to affect HCCI mixing, although large changes in volatility such as between gasoline and distillate fuels would be expected to have an effect.

CRC specified this project to be based on the blending of full boiling range refinery streams, rather than pure compounds.

\section{Recommendations}

The most prevalent refinery streams used for gasoline blending are reformate (about 50\% aromatic), alkylate (about 100\% iso-paraffin), cat cracker gasoline (about 25\% olefin), and straight run gasoline (about 100\% normal paraffin). Ten fuels are to be blended and evaluated in the first fuel set, and we recommend that these four streams be used to blend these fuels. The following characteristics and ranges of fuel properties are recommended as being most relevant for this fuel matrix:

1. Use four blending streams to manufacture the ten fuels (reformate, alkylate, cat cracker gasoline, and straight run gasoline). This considerably simplifies fuel blending while emphasizing refinery-based fuel blends. Fuel property blend modeling will be more accurate because of the use of well-characterized FBR components and will eliminate the need for iterative blending in achieving the final fuels.

2. Adjust all four blending streams as much as possible for a full gasoline boiling range equivalent to ASTM gasoline distillation class A. The result will be that all the blended fuels will meet this distillation class, and volatility and distillation will be eliminated as independent variables. For gasoline-range fuels, it is not expected that volatility will play a large role in mixture preparation. If desired, the Reid vapor pressure (RVP) of all fuels can be adjusted to 9 psi with butane.

3. Blend fuels to RON targets of about 92, 65 to 70, and a midpoint between. A RON of 92 represents the average RON in unleaded regular gasoline today [24]. It is very unlikely that going higher than this range will be of benefit to HCCI combustion. A RON of 65 to 70 is about the lowest value that can be achieved using FBR straight run gasoline and is therefore recommended as a lower limit for this study. A midpoint octane stresses the importance of octane as a variable for correlating combustion and knock performance and also for relating to current gasoline and refinery practices. Blending to exact RON values is not critical since the actual octane values achieved will be independent variables for data analysis. 
4. The three target ranges of RON can be achieved with multiple combinations of the blending streams, and it is expected that MON and octane sensitivity will vary with each blend formula. This will allow correlation of engine performance to octane values, octane sensitivity, and fuel chemistry. Three variations of fuel chemistry should be attempted for each RON level.

5. Fuel 10, a wildcard fuel, can be used to cover an additional variable or to check an idea that might be investigated in a second set of fuels. For example, fuel 10 might consist of one of the first nine fuels splash-blended with ethanol or splashblended with kerosene. Neat ethanol has been demonstrated to improve light-load HCCI combustion, and the addition of kerosene would be a very good way to enhance low-temperature heat release and lower fuel octane number beyond what we can achieve with gasoline components. Other refinery streams or pure components could be splash-blended for this fuel based on recommendations of the CRC committee.

\section{Recommended Blending Study}

Using the four blending streams, it is recommended that a parametric blending study be undertaken to determine multiple blend formulas that can achieve the target RON values of approximately 92 , midpoint value, and 65 to 70 . These multiple-blend formulas will then be screened for maximum variation in MON and fuel chemistry in order to select the final three fuel blends based on RON target. Design of experiment methods will be used to ensure the proper selection of the final blends.

\section{Independent Fuel Variables for Correlation to Engine Performance Parameters}

RON, MON, (R+M)/2, (R-M)

$\%$ aromatic, olefin, iso-paraffin, n-paraffin, c-paraffin 


\section{REFERENCES}

1. S. Onishi, S. Hong Jo, K. Shoda, P. Do Jo, and S. Kato. "Active ThermoAtmosphere Combustion (ATAC) - A New Combustion Process for Internal Combustion Engines." Society of Automotive Engineers, 1979, Technical Paper 790501.

2. H.J. Curran, P. Gaffuri, W.J. Pitz, and C.K. Westbrook. "A Comprehensive Modeling Study of n-Heptane Oxidation." Combustion and Flame, 1998. 114. pp. 149-177.

3. H.J. Curran, P. Gaffuri, W.J. Pitz, and C.K. Westbrook. "A Comprehensive Modeling Study of iso-Octane Oxidation." Combustion and Flame, 2002. 129. pp. 253-280.

4. F. Zhao, T.W. Asmus, D.N. Assanis, J.E. Dec, J.A. Eng, and P.M. Najt. Homogeneous Charge Compression Ignition (HCCI) Engines: Key Research and Development Issues. 2003, Warrendale, PA: Society of Automotive Engineers. pp. 658.

5. W.R. Leppard. "The Chemical Origin of Fuel Octane Sensitivity." Society of Automotive Engineers, 1990, Technical Paper 902137.

6. A.D.B. Yates, A. Swarts, and C.L. Viljoen. "Correlating Auto-Ignition Delays and Knock-Limited Spark-Advance Data for Different Types of Fuel." Society of Automotive Engineers, 2005, Technical Paper 2005-01-2083.

7. W.R. Leppard. "The Autoignition Chemistries of Primary Reference Fuels, Olefin/Paraffin Binary Mixures, and Non-Linear Octane Blending." Society of Automotive Engineers, 1992, Technical Paper 922325.

8. G.T. Kalghatgi. "Fuel Anti-Knock Quality - Part I. Engine Studies." Society of Automotive Engineers Technical Paper 2001-01-3584, 2001.

9. S. Tanaka, F. Ayalan, J.C. Keck, and J.B. Heywood. "Two-Stage Ignition in HCCI Combustion and HCCI Control by Fuels and Additives." Combustion and Flame, 2003. 132. pp. 219-239.

10. J. Andrae, D. Johansson, P. Bjornbom, P. Risberg, and G.T. Kalghatgi. "CoOxidation in the Auto-Ignition of Primary Reference Fuels and nHeptane/Toluene Blends." Combustion and Flame, 2005. 140. pp. 267-286.

11. G. Shibata, K. Oyama, T. Urushihara, and T. Nakano. "Correlation of Low Temperature Heat Release with Fuel Composition and HCCI Engine Combustion." Society of Automotive Engineers, 2005, Technical Paper 2005-010138.

12. P. Duret. "Gasoline CAE and Diesel HCCI: the Way towards Zero Emission with Major Engine and Fuel Technology Challenges." Society of Automotive Engineers, 2002, Technical Paper 2002-32-1787.

13. T. Aroonsrisopon, V. Sohm, P. Werner, D.E. Foster, T. Morikawa, and M. Lida. "An Investigation Into the Effect of Fuel Composition on HCCI Combustion Characteristics." Society of Automotive Engineers, 2002, Technical Paper 200201-2830.

14. M. Christensen, A. Hultqvist, and B. Johansson. "Demonstrating the Multi Fuel Capability of a Homogeneous Charge Compression Ignition Engine with 
Variable Compression Ratio." Society of Automotive Engineers, 1999, Technical Paper 1999-01-3679.

15. G.T. Kalghatgi, P. Risberg, and H.-E. Angstrom. "A Method of Defining Ignition Quality of Fuels in HCCI Engines." Society of Automotive Engineers, 2003, Technical Paper 2003-01-1816.

16. P. Risberg, G.T. Kalghatgi, and H.-E. Angstrom. "Auto-Ignition Quality of Gasoline-Like Fuels in HCCI Engines." Society of Automotive Engineers, 2003, Technical Paper 2003-01-3215.

17. G.T. Kalghatgi and R.A. Head. "The Available and Required Autoignition Quality of Gasoline-Like Fuels in HCCI Engines at High Temperatures." Society of Automotive Engineers, 2004, Technical Paper 2004-01-1969.

18. P. Risberg, G.T. Kalghatgi, and H.-E. Angstrom. "The Influence of EGR on Autoignition Quality of Gasoline-like Fuels in HCCI Engines." Society of Automotive Engineers, 2004, Technical Paper 2004-01-2952.

19. G.T. Kalghatgi. "Auto-Ignition Quality of Practical Fuels and Implications of Fuel Requirements of Future SI and HCCI Engines." Society of Automotive Engineers, 2005, Technical Paper 2005-01-0239.

20. A. Oakley, H. Zhao, N. Ladommatos, and T. Ma. "Dilution Effects on the Controlled Auto-Ignition (CAI) Combustion of Hydrocarbon and Alcohol Fuels." Society of Automotive Engineers, 2001, Technical Paper 2001-01-3606.

21. R. Collin, J. Nygren, M. Richter, M. Alden, L. Hildingsson, and B. Johansson. "The Effect of Fuel Volatility on HCCI Using Simultaneous Formaldehyde and OH PLIF." Society of Automotive Engineers, 2004, Technical Paper 2004-012948.

22. M. Christensen, B. Johansson, P. AmnJus, and F. Mauss. "Supercharged Homogeneous Charge Compression Ignition." Society of Automotive Engineers, 1998, Technical Paper 980787.

23. U.T. Turaga, Associate Scientist of Downstream Technology, ConocoPhillips. 2005, Personal Communication to James Szybist.

24. C.L. Dickson. "Motor Gasolines, Summer 2002." Northrop Grumman Mission Systems, 2003, No. 228, NGMS-228 PPS 2003/1. 